\title{
Los tres tiempos de la Comuna de París en Buenos Aires*
}

\author{
Martín Albornoz y Claudia Roman
}

$\mathrm{E}^{\mathrm{n}}$ una carta fechada el 28 de marzo de 1871, el representante diplomático argentino en París, Mariano Severio Balcarce, informaba a su ministro de Relaciones Exteriores que diez días atrás la Guardia Nacional y "el populacho parisino" se habían rebelado contra el gobierno francés. Testigo de lo que rápidamente comenzó a denominarse mundialmente como "Comuna de París", Balcarce se sintió a un tiempo estremecido y sorprendido al ver la bandera roja, "emblema de la república socialista", ondeando en el Hôtel de Ville:

La revolución de hoy es la más grave y la más peligrosa de cuantas la han precedido. Todas han sido de un carácter más o menos político, mientras que la presente es exclusivamente social llevada a cabo por hombres desconocidos [...] que para consolidar su usurpado poder no trepidarán en derramar a torrentes la sangre de sus conciudadanos. ${ }^{1}$

En el momento en que, dentro de una maleta diplomática, la carta de Balcarce arribó por

\footnotetext{
* Agradecemos a Lila Caimari por sus agudas observaciones.

${ }^{1}$ Carta de Mariano Balcarce al ministro de Relaciones Exteriores, 28 de marzo de 1871, Embajada en Francia, Diplomática y Consular, Caja 151, nota 23.
}

barco a Buenos Aires, la prensa de la ciudad comenzaba a acumular desordenadamente en sus columnas de noticias internacionales un sinnúmero de informaciones vinculadas a una serie de acontecimientos novedosos que todavía no encontraban una clara definición. $\mathrm{Ni}$ siquiera existía una forma precisa de designarlos, más allá de la referencia a dónde ocurrían: interpretados desde lejos, "los sucesos de París" difícilmente permitieran, incluso al lector más avezado, extraer las fuertes conclusiones del diplomático.

A priori, pocos acontecimientos del último tramo del siglo XIX tuvieron el potencial noticioso del episodio de la Comuna. En un tiempo brevísimo -tres meses entre principios de marzo y fines de mayo de 1871- tuvo lugar, de manera intensa y concentrada, una serie de hechos violentos y revulsivos que abrieron, siquiera momentáneamente, la posibilidad de transformar los vínculos sociales y las relaciones de poder en Occidente. Y esa oportunidad se producía, justamente, en $\mathrm{Pa}$ rís, la ciudad que desde Buenos Aires todavía se imaginaba como centro cultural del cual emanaba ese mundo que estaba a punto de cambiar. La lucha era social, política y armada; arrasaba las calles y modificaba efectivamente ese paisaje: las grandes movilizaciones de multitudes urbanas seguidas de grandes represiones, las barricadas alterando el plano 
de la ciudad y algunos episodios puntuales, como el derribamiento de la columna de Vendôme y el fuego haciendo arder los grandes museos del centro de París fueron a la vez efectos y símbolos de la brusca transformación de la ciudad y del que se suponía su correlato inseparable, la reconfiguración de las relaciones de fuerza políticas y sociales. Tinta y petróleo fueron las dos sustancias más mencionadas en los relatos que circularían para tratar de dar forma a la Comuna. Sus usos eran nuevos, porque lo que buscaban narrar también lo era.

No faltaron, como puede advertirse en esta breve reseña, ni acontecimientos contundentes y significativos, ni sorpresa en su devenir, ni pertinencia para su repercusión. Los pocos estudios referidos al impacto de la Comuna en la Argentina parecieran traducir sin pérdida de elemento alguno esa plenitud. Entendida como un primer escalón en la internacionalización del comunismo, se ha señalado que, leídos en Buenos Aires, sus sentidos inmediatos fueron claros. Es decir, que cualquiera que pasase las páginas de los diarios porteños sacaría una misma conclusión: los sucesos de París habrían expresado la confirmación de que el fantasma del comunismo no solo recorría Europa, sino también Sudamérica. ${ }^{2}$ Sin embargo, al revisar los periódicos porteños de entre abril y agosto de 1871, surge una impresión contraria: a los lectores les llegaban informaciones dispersas y heterogéneas que, posiblemente por el desarrollo abierto de los sucesos, no configuraron en principio un acontecimiento nítido o diferenciado de las noticias de la guerra europea. Entre el fárrago de novedades, comentarios e interpretaciones que ocupaban a la prensa, la Comuna de París no encontraba un perfil pro-

\footnotetext{
${ }^{2}$ Una interpretación en esta línea puede verse en Horacio Tarcus, Marx en la Argentina. Sus primeros lectores obreros, intelectuales y científicos, Buenos Aires, Siglo XXI, 2007, pp. 62-66.
}

pio y su proceso no terminaba de generar expectativa. Al leer y recortar las novedades de la prensa extranjera, la que llegaba a través de cartas privadas, $\mathrm{o}$ al parafrasear las noticias impresas por otros periódicos, los redactores porteños no lograban ordenar los sucesos parisinos en una narración convencional, ni siquiera en una serie abierta. "La situación de París es muy delicada; ni acaba de estallar, ni pierde su gravedad", evaluaba, con prudencia, La Opinión Nacional de Rosario en su edición del 26 de abril de 1871. Esa percepción de inminencia que impedía al redactor organizar un relato completo, pero al mismo tiempo lo estimulaba a dejar insinuada la que podría ser una "primicia" importante, describe el tono justo con el que la prensa de esta región apunta, inicialmente, que "eso" que todavía no era un acontecimiento de un momento a otro podría ocupar las primeras planas.

Tal indefinición tiene varias explicaciones. Algunas tienen que ver, de diferentes formas, con el proceso del que emanaban los hechos: la dinámica de los sucesos, inscriptos en las estribaciones de la Guerra Franco-Prusiana (1870-1871) pero a la vez súbita y confusamente desviados en sus objetivos de ese conflicto, por un lado; lo fragmentario de las informaciones que circulaban allí mismo, en parte por las dificultades que imponía el sitio de las fuerzas prusianas a París, por otro. Incluso los sentidos del término "Comuna" que circularon entre sus protagonistas fueron muy variados y hasta contradictorios, y dependieron, como señala John Merriman, de sus propias "actitudes y lealtades". ${ }^{3}$ Por otra parte, las condiciones de circulación trasatlántica de esas novedades, a través de un sistema híbrido de noticias personales -cartas privadas y públicas, y de otras vías más lábiles, como los relatos de viajeros-y "maletas" de correspon-

\footnotetext{
${ }^{3}$ John Merriman, Masacre. Vida y muerte en la Comuna de París, Madrid, Siglo XXI, 2017, p. 46.
} 
dencia y telegramas, sumaron a aquellas condiciones de origen una serie de capas discontinuas de narración que, por efectos de ese sistema, no siempre llegaban en orden a destino, ni se procesaban y publicaban de manera unívoca. Una observación inicial del conjunto de la prensa de Buenos Aires permite afirmar que, durante los primeros meses de 1871, la recepción de las informaciones de la Comuna estuvo marcada por un ritmo sincopado, en el que no todos los eventos pudieron ser codificados rápidamente en términos de una narración noticiosa que lograra interpelar tanto a directores, editores, redactores e ilustradores de prensa locales como, a los lectores -ni suscitar, en ellos, respuestas nítidas- ${ }^{4}$ Por lo demás, por curiosas o peculiares que resultaran las repercusiones de la Comuna de París en Buenos Aires, eran también resultado de un proceso más complejo que hacía de la insurrección parisina un fenómeno global. Este dato no fue desconocido para los lectores contemporáneos aunque, nuevamente, su decodificación podía no ser evidente. Así, un lector de La Prensa podía enterarse de que en Chicago, de forma casi simultánea, había tenido lugar una manifestación por la situación francesa, incluso cuando no supiera con exactitud, previamente a la lectura de la noticia, cuál era exactamente esa "situación" francesa que motivaba la movilización. ${ }^{5}$ Un último elemento a considerar es la fuerte presión de las novedades locales que, como se verá, tuvie-

\footnotetext{
${ }^{4}$ Sobre el ritmo de las noticias internacionales en la prensa porteña de este período, Lila Caimari, "En el mundo-barrio. Circulación de noticias y expansión informativa en los diarios porteños del siglo XIX", Boletín del Instituto de Historia Argentina y Americana Dr.

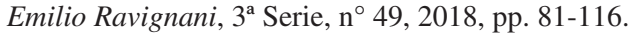

${ }^{5}$ Esa capacidad de interconectar contextos, como sostiene Quentin Deluermoz, formó parte de la construcción misma del acontecimiento y sería determinante para su apropiación posterior como eslabón clave de la historia de la izquierda internacionalista. Véase Quentin Deluermoz, Commune(s), 1870-1871: Une traversée des mondes au XIXe siècle, París, Seuil, 2020.
}

ron una particular intensidad durante los meses en que se producían los eventos que más tarde se recortarían nítidamente como la Comuna de París. Los "hechos locales" -para retomar la denominación que solía usar la prensa de época- añadieron una última dimensión que, al igual que las ya mencionadas, no fue estrictamente privativa de la recepción porteña de la noticia, pero presentó desafíos particulares para su conceptualización como tal.

La recepción de la Comuna de París en la prensa de Buenos Aires, en suma, permite advertir un "caso" de configuración diferida de la noticia. En ese diferimiento, la noticia se tramó, con valencias distintas, en tres tiempos. En un primer momento, fue un evento que no logró perfilarse de manera autónoma y distinta del flujo de "los sucesos de París" y que, además, no se decodificó únicamente en serie política. Pocos años más tarde se despliega un segundo momento, en el que un sesgo o una serie particular de los acontecimientos dentro de su trama fueron actualizados en sede local, en función de sucesos noticiosos significativos que tuvieron lugar en Buenos Aires, de importancia fundamentalmente política, e interpretados en clave facciosa. Así, la noticia internacional se configuró retrospectivamente: la narración de los hechos y de su sentido se daban por conocidos, y se utilizaban como presupuesto, sin debate, para enmarcar y ordenar en una línea causal-cronológica y, además, teleológica, una noticia local de la coyuntura inmediata. En un tercer momento, más alejado aun en el tiempo y cuya interpretación ha sido más difundida, en sincronía con lo que ocurrió en términos globales, la noticia de la Comuna devino definitivamente en un emblema: plenamente autónoma, pudo utilizarse para movilizar cultural, política y colectivamente un conjunto de ideas y representaciones asociadas al mundo de las izquierdas. Paradójicamente, la noticia tardía se volvía actual 
y eficaz en todas las dimensiones (discursiva, ideológica, pragmático-movilizadora) en que buscaban serlo los hechos que la originaron.

\section{1}

En la mayoría de los medios porteños, las primeras noticias de la Comuna se insertaron con poca nitidez, como apostillas o "notas de color" derivadas de la primera "fiebre noticiosa" de la prensa porteña, disparada por la Guerra Franco-prusiana. ${ }^{6}$ En Buenos Aires, esa "enfermedad" metafórica resulto concomitante con el más literal avance de la "fiebre amarilla" en la Argentina, que tuvo un pico entre el fin del verano y el principio del otoño, es decir, en los meses durante los cuales se sucedieron los hechos de la Comuna. Mientras iban llegando al sur las noticias de lo que ocurría en París, el avance y las consecuencias de la epidemia de fiebre amarilla y de las decisiones gubernamentales para controlarla ocuparon grandes parrafadas editoriales en todos los diarios, que además transcribían, en una verdadera "novela" por la complejidad de su trama y el tratamiento de sus personajes, polémicas de diverso calibre sobre las intervenciones oficiales y civiles, y una seguidilla de relatos de "casos" y de sueltos de diferente tono (ocasionalmente, incluso humorísticos) sobre las víctimas de ese mal. La epidemia provocó, por último, el cierre de algunos medios durante los meses de mayor virulencia de la enfermedad, lo que suspendió de hecho toda otra información de prensa. Los diarios porteños informaban también, por entonces, de otros peligros: la rebelión de López Jordán

\footnotetext{
${ }^{6}$ Véase Sergio Pastormerlo, "Sobre la primera modernización de los diarios en Buenos Aires. Avisos, noticias y literatura durante la Guerra Franco-Prusiana (1870)", en V. Delgado y G. Rogers (eds.), Tiempos de papel: Publicaciones periódicas argentinas, La Plata, Universidad Nacional de La Plata, 2016, pp. 13-37.
}

en el Litoral preocupaba todavía al gobierno nacional y llenaba grandes tramos de sus primeras páginas, completando un panorama en el que los episodios de París se presentaban como restos noticiosos de una gran guerra internacional, útiles para terminar de llenar la sección correspondiente pero en modo alguno aspirantes a ser titulares en torno a los que girara cada edición.

A fines de junio de 1871, Mardoqueo Navarro, autor de un polémico Diario de la epidemia en Buenos Aires que se publicaba por entregas en el matutino porteño La República, dio por cerrado su texto con una entrega de economía extraordinaria: "22 de junio: La epidemia: olvidada. El campo de muertos de ayer es el escenario de los cuervos de hoy: Testamento y concursos, edictos y remates son el asunto. ¡iiAy de ti Jerusalem!!!". ${ }^{7}$ Esa semana, el mismo periódico proclamaba que "la insurrección de París" estaba vencida. La información, tentativa, de que algo más que el asedio alemán inquietaba a la capital francesa había comenzado a filtrarse en La República unos dos meses antes, el 16 de abril.

Según afirma Pastormerlo, las noticias sobre la Guerra Franco-Prusiana se ordenaban en su publicación en sucesión cronológica, y por eso podían leerse en serie, como un folletín (y eventualmente, podían desplazar sin mayores dificultades las piezas más seductoras de la literatura local, suspendiendo el folletín literario para dejar espacio en las columnas a la información internacional). En los periódicos relevados que corresponden a este primer momento de recepción noticiosa local, en cambio, la información sobre la Comuna funcionó justamente de modo opuesto y complementario: las piezas de su eventual relato aparecían de manera discontinua y dis-

\footnotetext{
${ }^{7}$ Reproducido en Miguel Ángel Scenna, Cuando murió Buenos Aires, 1871, Buenos Aires, Ediciones La Basti1la, 1974, p. 439.
} 
persa, sin que fuera posible imaginarlas como parte de una narración seriada. ${ }^{8}$

Un breve suelto de La República sintetizaba -en el sentido químico del término- las coordenadas desde las que el diario interpretaba el proceso francés: "Las noticias de Europa. Han producido una honda sensación las recibidas ayer. Se ve que París es el asiento de una mazhorca [sic] tan desenfrenada como la que en otra época existió entre nosotros. Las noticias comerciales sobre el buen precio de los mercados europeos de nuestros cueros y lanas han animado mucho el comercio". ${ }^{9} \mathrm{La}$ Comuna no alarmaba, y no se percibía como algo nuevo. Muy por el contrario, con cierta condescendencia, la clave de la "barbarie" local permitía entender a la vieja Europa. Los incendios, la violencia popular en las calles y la destrucción no eran ni podían ser noticia en Buenos Aires, porque eran eventos superados que estaban, en todo caso, en su pasado. En tanto la balanza comercial internacional siguiera favoreciendo a la Argentina, el futuro estaría asegurado. Menos de una semana más tarde, el mismo diario dio por cerrado el episodio: "La insurrección de París está completamente vencida", anunciaba (basándose en la información que reportaba lo ocurrido "hasta el 14 de junio", recibida a través del "Patagonia"). ${ }^{10}$ Aunque el diario sacara el máximo provecho, en ediciones sucesivas, de todos los recortes de la valija informativa llegada por ese barco, su efecto noticioso estaba ya neutralizado. A partir de fines de junio apenas hay menciones a la Comuna. El 30 de ese mes, de hecho, una nota en primera plana proponía un balance comparativo del estado urbanístico de Buenos Aires y de París. El resultado era definitivamente perdidoso para la primera: la ciudad arrasada por la fiebre amarilla estaba más cerca desde todo punto de vista, y resultaba una imagen más potente y patética que una París que, a la distancia y pese a la guerra, se mostraba como debía conservarse en la memoria porteña: monumental, sin referencia alguna a los incendios, casi intacta. Incluso cuando en la última columna de esa misma primera plana otra nota informara sobre "El incendio de Francia". ${ }^{11}$

\section{5}

Cuatro años más tarde, el léxico brumoso de la revolución social y las palabras y las figuras novedosas que la Comuna de París había irradiado desacompasadamente sobre la prensa de Buenos Aires tendría sentidos más nítidos. Al cerrado rechazo de los fundamentos y las consecuencias de los sucesos europeos que manifestaron figuras como Domingo Faustino Sarmiento se sumó un coro de personalidades políticas que, aunque abrumado, podía tomar la insurrección de París como antimodelo edificante. ${ }^{12}$ El 11 de noviembre de 1875 , en la inauguración del parque Tres de Febrero, diseñado sobre lo que habían sido los terrenos de la quinta de Juan Manuel de Rosas, "el tirano de Southampton", Nicolás Avellaneda plantó una magnolia. Era un gesto

\footnotetext{
${ }^{8}$ Pastormerlo, "Sobre la primera modernización", p. 24. El corpus de prensa aludido incluye una docena de diarios y semanarios, casi todos impresos en Buenos Aires. Si bien la investigación involucra un conjunto más amplio y que está aún en construcción, a los fines de este trabajo se seleccionaron las publicaciones de mayor tirada y aquellas que aportaban una nota distintiva al proceso de recepción de la noticia global.

${ }^{9}$ La República, "Hechos locales", 21 de junio de 1871.

${ }^{10}$ Ibid., "Exterior", 27 de junio de 1871.
}

${ }^{11}$ Ibid., "París y Buenos Aires", 30 de junio y 1 de julio de 1871, "El incendio de París", Ibid. Desde el día anterior, la primera noticia de "Exterior" no era sobre Francia, sino acerca de Montevideo.

${ }^{12}$ Por ejemplo, en el caso de Sarmiento, de su lado del Atlántico, la Comuna de París, "incendio y sumisión", era un buen ejemplo de por qué debía abandonarse el anhelo revolucionario como forma de intervención política. Véase Domingo Faustino Sarmiento, Obras. Tomo XXI, Buenos Aires, Imprenta Mariano Moreno, 1899, p. 60. 
inaugural, un nuevo comienzo, contrario al brío apocalíptico que había guiado a los comuneros. Para Avellaneda, la Comuna podía funcionar ya como una simple evocación:

Después de haber visto levantarse en las márgenes del Sena aquella Comuna de $\mathrm{Pa}$ ris ilustrando su horror a la tiranía con los resplandores de la antorcha del incendiario, cuando la llama del petróleo había quemado el Louvre porque la edificaron los monarcas del derecho divino, y las Tullerías porque se desplegara allí entre pompas Imperiales el despotismo armado que gobernó la Europa al redoble de sus tambores, no debimos ni pudimos pensar que era menester, en odio al tirano, sembrar de sal este suelo, y abandonarlo para siempre, dejando crecer la yerba en los caminos. Pensamos más acertadamente. Creímos que el horror á las tiranías puede convertirse en un sentimiento de destrucción ciega, cuando no se halla vivificado por el amor al progreso y á la libertad. El espíritu de los pueblos libres es cristiano. No es iconoclasta. Depura, restaura, santifica el monumento con nuevas advocaciones; pero no lo destruye. Era mejor convertir la mansión sombría del tirano cauteloso en jardines cultivados al uso del pueblo. ${ }^{13}$

El sistema de referencias que expone la cita y las formas en que se articula argumentativamente revelan un sentido más preciso si se lo considera en el marco de un suceso local muy presente para quienes leyeran o escucharan el discurso de Avellaneda: el incendio del Colegio del Salvador de Buenos Aires, ocurrido unos nueve meses antes, el 28 de febrero de 1875. A partir de un conjunto de fuentes heterogéneas que permiten acceder a los puntos de vista de los diferentes actores involucrados,

${ }^{13}$ La Tribuna, 12 y 13 de noviembre de 1875.
Hilda Sabato ha reconstruido las percepciones de liberales y católicos, políticos oficialistas y de la oposición, de las autoridades de la Iglesia y de instituciones civiles y políticas involucradas en un episodio que, de manera notable, se recortaba en principio como inédito en el contexto de las prácticas de movilización civil de la época. Su lectura matiza el carácter de esa disrupción, y analiza otras modulaciones de la Comuna de París en la prensa oficial y de oposición, así como en el discurso de algunos actores individuales. De este modo, se verifica que la Comuna emergía como una imagen que permitía evocar y yuxtaponer una serie de rasgos (violencia incendiaria, carácter plebeyo y desbordado del avance sobre la ciudad, reivindicaciones no solo anticlericales, sino internacionalistas y antiestatales) que habilitaban atribuir la culpa de los desbordes y los excesos en la esfera pública a participantes marginales por su clase, por su ideología y por su pertenencia étnica: inmigrantes. La reconstrucción historiográfica muestra con claridad, en cambio, que quienes estaban más comprometidos con los sucesos del incendio del Colegio del Salvador eran jóvenes argentinos y, en su mayoría, porteños; y que los intentos de involucrar a algunos integrantes de la sección francesa de la Asociación Internacional de Trabajadores de Buenos Aires habrían sido ineficaces por la propia actitud frente a los hechos de estos virtuales "agitadores". La construcción de las analogías entre el episodio del incendio y la Comuna como parte del contexto internacional se conjugaría, en todo caso, con un antecedente más próximo en el tiempo y territorialmente presente, aunque silenciado por la prensa: la movilización local ligada a la violencia facciosa durante todo el año anterior, a partir de las elecciones legislativas y la revolución mitrista. ${ }^{14}$

\footnotetext{
${ }^{14}$ Parafraseamos sucintamente hasta aquí el análisis incluido en Hilda Sabato, La política en las calles. Entre el
} 
Recordando la ocasión del discurso de Avellaneda y las referencias de algunas otras fuentes, quizá sea útil agregar como elemento adicional que esa violencia súbita, plebeya y caracterizada como inesperada y marginal fue ligada sin mayores dificultades, como ya lo había insinuado aquel suelto de 1871 de $L a$ República, a otro imaginario aún productivo para los contemporáneos a través de su símbolo más acabado y eficaz en términos comunicativos: el del rosismo y la mazorca. $\mathrm{Su}$ evaluación con referencia al presente, sin embargo, era novedosa, y expresaba una visión bastante menos serena y optimista que la que, poniendo la mazorca en el pasado, sostenía aquel. Aunque no se buscaba involucrar al estado nacional o de Buenos Aires ni a la policía como agentes de los disturbios, la apelación a la mazorca condensaba, en la clave que Sarmiento había formulado tres décadas atrás, uno de los modos en que la "barbarie" tomaba, como si fuese externa a ella, posesión de la ciudad. El elemento plebeyo de la multitud que se añadía más puntualmente a esa configuración permitía, de paso, sincronizar la actualidad local con lo que ocurría a escala global. ${ }^{15}$

voto y la movilización. Buenos Aires, 1862-1880, Buenos Aires, Sudamericana, 1998, especialmente pp. 217-270.

${ }^{15}$ Otro ejemplo de este movimiento interpretativo puede encontrarse en el "Proyecto de Manifiesto" sobre el incendio del Colegio del Salvador que el senador Miguel Navarro Viola presentó ante la Cámara de Buenos Aires el 2 de marzo de 1875: "[...] Que esta vez es la primera que cosa semejante se ha hecho en territorio argentino fuera de los incendios causados por los bárbaros del desierto, el lujo de la destrucción ha sido excedido por los bárbaros de la civilización que derramaban petróleo y alquitrán y escalaban por muchos puntos el magnífico edificio elevado sobre un cuadrado de 150 varas y que costaba muchos millones de pesos [...]". La "barbarie de la civilización" y su anticipado corolario, el "lujo de la destrucción", son fórmulas de evidente matriz sarmientina, alusivas al rosismo. Véase Miguel Navarro Viola, "Documento del Doctor Navarro Viola. Proyecto de Manifiesto", El Católico Argentino, II, n 33, 13 de marzo de 1875 , pp. 527-528.
Una muestra algo menos sutil de derrame léxico en línea con la de aquel discurso de Avellaneda puede leerse en El Petróleo. Órgano de las últimas capas sociales y de las primeras blusas comunistas, semanario satírico ilustrado que comenzó a editar en marzo de 1875 el español republicano Eloy Perillán Buxó. Atento a las resignificaciones del imaginario de la Comuna que habilitaba la situación local, Perillán Buxó - un periodista español acostumbrado a ensayar la combatividad republicana a través de la prensa- no dudó en aclimatarlo ni en desplegar todo un campo léxico que lo ponía en juego: cada número del semanario era una "rociada"; quienes lo vendían, "petroleros"; los redactores firmaban como "Petrolino" o "Glicerino", por ejemplo. Para los lectores porteños, la novedad de la violencia en las calles se interpretaba a través de su "reconocimiento" en la evocación del vocabulario de la Comuna, reversionado satíricamente en la prensa local. El efecto resulta, antes que ideológico en sentido estricto, sensacionalista: desde su primera nota editorial, lejos de mostrarse comunista, el semanario se definió como únicamente "fiel a su público", y su rasgo verbal más audaz fue, módicamente, el de distanciarse tanto de mitristas como de alsinistas. La primera lámina ilustrada que incluyó El Petróleo, sin embargo, fue bastante más elocuente y eficaz, y puede pensarse como una suerte de "editorial gráfica" en términos de su apropiación y actualización del completo episodio de 1871 .

En la imagen, como puede advertirse, un sujeto barbudo y desencajado pregunta: “ ¿Hay por aquí un arzobispo?", mientras sostiene su botella de "kerosén" y contempla tanto el incendio de Buenos Aires como el "vuelo" de capitales hacia Europa amparado por la Iglesia, caricaturizada en la figura del arzobispo de Buenos Aires, Monseñor León Federico Aneiros. La alegoría de la República, sentada y apoyada sobre una columna trunca en la que se lee el nombre del semanario, se muestra 


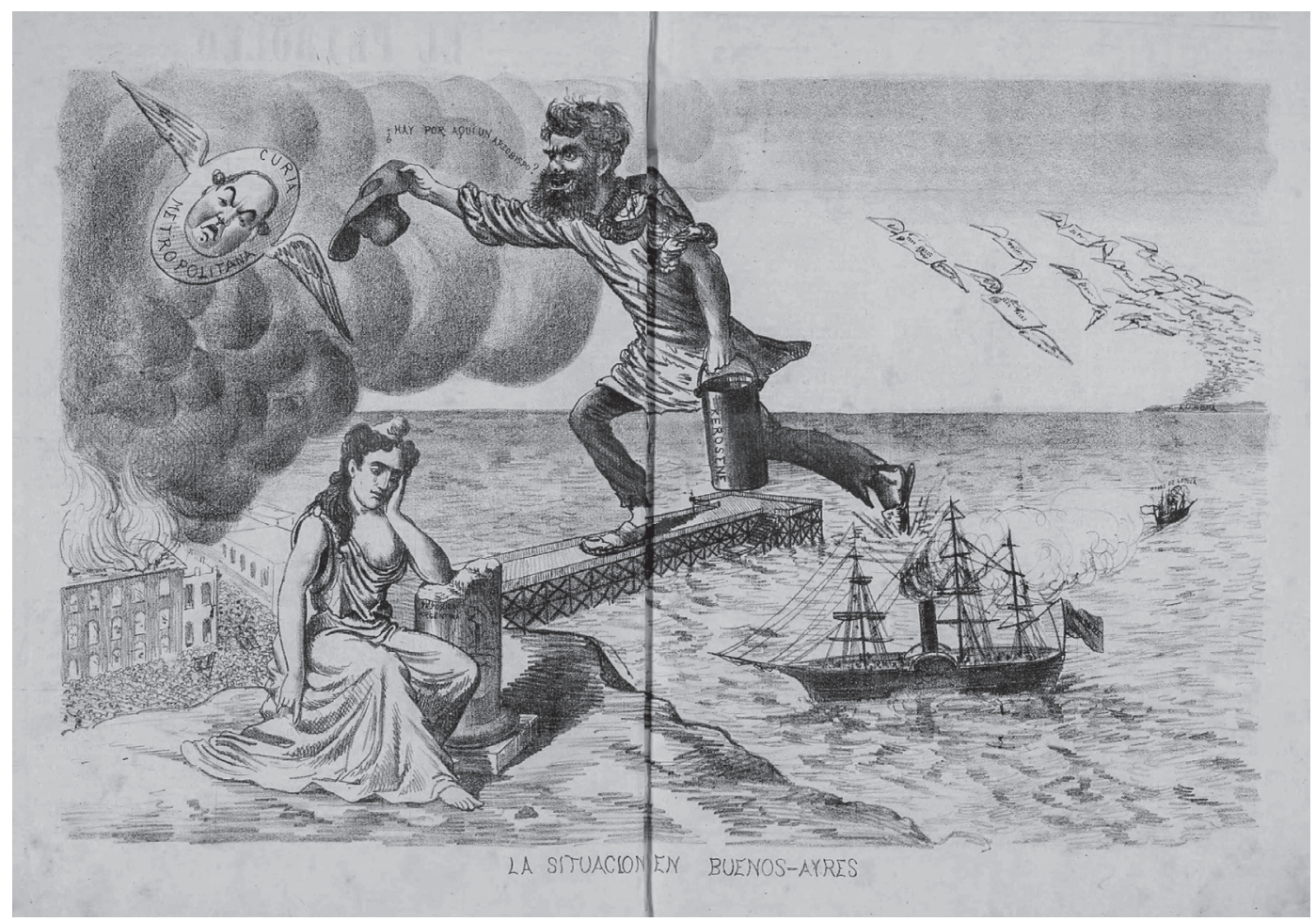

El Petróleo. Órgano de las últimas capas sociales y de las primeras blusas comunistas, I, 1, 5 de marzo de 1875, pp. 2-3. Sin firma.

completamente desacralizada, desolada en la doble acepción de tristeza y soledad que carga el término, y de espaldas a una multitud, figurada como un continuo de círculos grises y difusos que convoca el incendio del Colegio. La lámina interpreta y también, en este caso, produce la noticia: activando el imaginario y el vocabulario comunards como si no hubiera dudas sobre su sentido, advierte que la Comuna no está en el pasado parisino sino en el presente porteño; no ocurre allí, sino aquí.

\section{7}

Un ejemplo de torsión novedosa y modernista de los significados de la Comuna puede leerse en el periódico La Montaña, que los jóvenes socialistas José Ingenieros y Leopoldo Lugo- nes publicaron en Buenos Aires en 1897. El primero, en un texto titulado "Semana de mayo, 1871", destruía la temporalidad del acontecimiento parisino y, arrancándolo del pasado, lo volvía umbral de un nuevo tiempo. Como rezaba el subtítulo, para Ingenieros la Comuna debía considerarse un "bautismo de sangre". La coloración confusa de la noticia internacional era anulada; las connotaciones funestas, invertidas. La bandera roja era un "santo harapo"; la barricada, "el altar del pueblo"; la petrolera, una madre "hermosa y pálida" en cuyos ojos se vislumbraba "la expresión del infinito". ${ }^{16}$ Los nuevos tiempos estaban marcados también en la vida misma del periódico,

${ }^{16}$ José Ingenieros, "Semana de mayo, 1871”, La Montaña, Año I, $\mathrm{n}^{\circ}$ 4, 15 de mayo de 1897. 
que desde su primer número tuvo una doble datación, fechado a la derecha del lector con referencia al calendario gregoriano ("Buenos Aires, 1er. de abril de 1897" con el significativo agregado "(E.V. [vg., "era vulgar"])" y a su izquierda, postulando como origen de los tiempos nuevos a la Comuna de París ("12 Vendimiario del año XXVI de la Comuna").

Hacia fines de siglo, esa doble temporalidad que La Montaña ponía en juego para evidenciar el desvío revolucionario en el interior de la "era vulgar" podía verificarse, de manera más general, en las diferentes formas en que la Comuna de París ingresaba al calendario conmemorativo de movimientos que, reformistas o revolucionarios, socialistas o anarquistas, articularon en la ciudad una serie de prácticas y discursos en torno de ese "origen". La naciente prensa de izquierda no tenía duda sobre su positiva importancia.

Sin embargo, por mucho que la vocación conmemorativa de izquierda pugnara por atribuir un sentido último y eficaz a la Comuna de París, era sencillamente imposible anular otras significaciones menos solemnes y alarmadas que, aún a comienzos del siglo $\mathrm{xx}$, era posible detectar. Un ejemplo: el 9 de enero de 1905 moría en Marsella, ya anciana, Louise Michel, militante símbolo de los sucesos que habían conmocionado a París más de tres décadas atrás. Tomando nota del deceso, un cronista en La Nación redactó una vistosa y extensa columna que, acompañada de una fotografía, buscaba en un mismo movimiento desentrañar el enigma revolucionario de París y los vericuetos biográficos de Louise Michel. El resultado, francamente humorístico, no parecía alimentar las pesadillas del burgués respecto de lo que en las narrativas de izquierda anticipaba la Comuna. Por el contrario, aventuraba otra explicación para su heroísmo: "Luisa Michel nunca fue bella, ni siquiera graciosa. Su aspecto, poco agradable en la juventud, volvióse en la vejez de una fealdad rara en su sexo ¿Habrá sido esta condición es- pecial, la que, quitándole la esperanza de ser amada, elevó y dilató su espíritu hacia un amor más grande e indefinido, pero generoso y noble para todo el género humano?"17

\section{Impacto en tres tiempos}

La recepción periodística de la Comuna de $\mathrm{Pa}$ rís en la prensa porteña permite advertir sus efectos en tres tiempos, ampliamente dilatados. En el momento inicial, relativamente sincrónico de los acontecimientos, las informaciones publicadas por los periódicos fueron dispersas y discontinuas, sin llegar a configurar el episodio de la Comuna como una serie autónoma, con potencia noticiosa. Este antecedente resultaría, sin embargo, imprescindible para que un conjunto de elementos presentes o no en esa recepción inicial se rearticularan cuatro años más tarde, cuando la situación local y la coyuntura internacional permitieron actualizar y precisar un vocabulario para mencionar a la Comuna como una referencia o contrapunto para otros sucesos locales, así como asociarle de manera consistente ciertas imágenes y ciertos motivos discursivos. Todo eso permitió que la Comuna operara como una

17 "Luisa Michel”, La Nación, 10 de enero de 1905. Quizá convenga recordar que para entonces La Nación era uno de los diarios que había atravesado el proceso de modernización de la prensa porteña, que incluyó aspectos materiales y técnicos decisivos (como la incorporación regular del servicio telegráfico), un salto significativo en las cifras de sus ejemplares -acorde a la multiplicación del público lector-, la profesionalización de reporters y trabajadores gráficos y, sobre todo, la ampliación de las funciones de la prensa, en las que la información noticiosa y el entretenimiento se enlazaban de maneras novedosas y atractivas. La Nación no fue el único medio en acudir a la figura de la "virgen roja" de manera casi despolitizada, a través de las reapropiaciones más extravagantes. Poco más tarde, magazine Caras y Caretas, por ejemplo, publicaría, bajo el título de "Una propagandista", una publicidad del Tricófero de Barry, cuyo uso frecuente evitaría caer en las "vulgaridades" y "machonerías de la política" en las que había incurrido Louise Michel (Caras y Caretas, 3 de diciembre de 1910, p. 154). 
noticia ya configurada en el pasado y, de ahí, como reservorio de certezas y de evaluaciones axiológicas a las que podía acudirse como precedente o paralelo de sucesos que estaban desarrollándose -es decir, de los que iban tomando forma como otras noticias- y también como recurso para explicar las motivaciones de los actores locales involucrados en ellos. En ese momento, la Comuna volvió inteligible la violencia urbana en Buenos Aires y reverberó, en diferido, pero con intensidad, en los públicos lectores porteños. Tendrían que pasar todavía más de veinte años para que la mirada de algunos jóvenes intelectuales y periodistas de diferentes procedencias y afiliaciones ideológicas anclaran su relato como símbolo eficaz y, sobre todo, para que su sentido se eslabonara de manera dominante y precisa en una memoria de las luchas políticas de las izquierdas. Para quienes escribían y leían la prensa contemporánea a los sucesos, en cambio, esos sentidos fueron probablemente mucho más generales, difusos y contradictorios. Por lo demás y más allá de su excepcionalidad como acontecimiento, la recepción diferida de la Comuna de París en la prensa de Buenos Aires podría considerarse como un "caso" que permite iluminar modalidades específicas de la construcción de una red noticiosa internacional desde una perspectiva local. Una paradójica noticia en tres tiempos recoge así las condiciones materiales de su circulación y las posibilidades efectivas de su recepción y decodificación locales de la información global.

\section{Bibliografía citada}

Caimari, Lila, "En el mundo-barrio. Circulación de noticias y expansión informativa en los diarios sudamericanos del siglo xix", Boletín del Instituto de Investigaciones en Historia Argentina y Americana "Dr. Emilio Ravignani”, $3^{\text {a }}$ Serie, $\mathrm{n}^{\circ} 49$, segundo semestre de 2018 , pp. 81-116.

Conrad, Sebastian y Dominic Sachsenmaier, "Introduction: Competing Visions of World Order: Global Moments and Movements, 1880s-1930s", en S. Conrad y D. Sachsenmeier (eds.), Competing Visions of World Order, Nueva York, Palgrave-MacMillan, 2007, pp. 1-6.

Deluermoz, Quentin, Commune(s), 1870-1871: Une traversée des mondes au XIXe siècle, París, Seuil, 2020.

Merriman, John, Masacre. Vida y muerte en la Comuna de París, Madrid, Siglo xxI, 2017.

Pastormerlo, Sergio, "Sobre la primera modernización de los diarios en Buenos Aires. Avisos, noticias y literatura durante la Guerra Franco-Prusiana (1870)", en V. Delgado y G. Rogers (eds.), Tiempos de papel: Publicaciones periódicas argentinas (siglos XIX-XX), La Plata, Universidad Nacional de La Plata, 2016.

Sarmiento, Domingo F., Obras. Tomo XXI, Imprenta Mariano Moreno, Buenos Aires, 1899.

Sabato, Hilda, La política en las calles. Entre el voto y la movilización, 1862-1880, Buenos Aires, Sudamericana, 1998.

Scenna, Miguel Ángel, Cuando murió Buenos Aires, 1871, Buenos Aires, Ediciones La Bastilla, 1974.

Tarcus, Horacio, Marx en la Argentina. Sus primeros lectores obreros, intelectuales y científicos, Buenos Aires, Siglo XXI, 2007. 


\section{Resumen/Abstract}

\section{Los tres tiempos de la Comuna de París en Buenos Aires}

Este trabajo estudia la recepción noticiosa de la Comuna de París en los diarios de Buenos Aires. Pese a su altísimo impacto social y político a mediano plazo, su repercusión noticiosa inmediata fue módica. Un relevamiento más extendido muestra que su impacto se construyó a lo largo de tres momentos. Mientras tenían lugar los hechos (1871), no llegó a conformarse un relato unívoco y las informaciones publicadas fueron confusas y dispersas. En 1875, un hecho puntual -el incendio del Colegio del Salvadorhizo emerger un relato consistente y definido, que sirvió para ponderar la actualidad local. Hacia 1897, algunos intelectuales y periodistas produjeron un cambio en su evocación y contribuyeron a su incorporación definitiva al calendario de las izquierdas. Este caso de recepción "en tres tiempos" permite además conocer mejor las condiciones y efectos de la circulación informativa global en la prensa porteña del último tercio del siglo XIX.

\section{Palabras clave}

Comuna de París - Noticias globales - Prensa porteña - Impacto noticioso

\section{The Three Stages of Paris Commune in Buenos Aires}

This essay aim is to study the reception of Paris Commune in Buenos Aires newspapers. Despite the social and political impact, it would have later on, the press barely reflected the facts when they were happening. A more extended analysis shows that the Commune became a "news" over three moments. A univocal account could not take form and the published information was confused and scattered while the events were taken place (1871). Afterwards (1875), a specific event -when the Colegio del Salvador was set on fire- brought out a consistent and defined history, which served to weigh up local events. Around 1897, some intellectuals and journalists produced a change in its evocation and contributed to make it a milestone for local left's movements. This reception "in three stages" also allows a better understanding both of conditions and effects of global news circulation in Buenos Aires press of the last third of XIXth.

\section{Keywords}

Paris Commune - Global News - Buenos Aires

Periodical Press - News Impact 